\title{
Research on the performance models of several urban types of SUV automobiles based on analytic hierarchy process
}

\author{
Hui Kang ${ }^{1, a}$, Shuo Zhou ${ }^{2, b}$ and Yong Wang ${ }^{2, c}$
}

${ }^{1}$ School of mechanical engineering, North China Electric Power University, Baoding 071000, China;

${ }^{2}$ School of mechanical engineering, North China Electric Power University, Baoding 071000, China.

a1018904296@qq.com, bzhoushuo1230@sina.com

Keywords: Analytic Hierarchy Process, Urban Types of SUV automobiles, Indication System.

\begin{abstract}
In the field of automobile design, evaluation on the comprehensive performance of using analytic hierarchy process for quantitative processing, analysis and research according to several SUV with about 200000 of automobile power, fuel consumption, safety, price and humanization design, make the evaluation more objective, scientific.
\end{abstract}

\section{Introduction}

SUV is a kind of comfort and space function also has a wagon like plus truck traction and off-road ability of the vehicles. Because of the MPV type seat combination function, make the vehicle space utilization rate is higher, both manned and cargo, wide scope of application. With the increasing living standards improve SUV by people favor. This paper attempts to evaluate the comprehensive performance by the method of AHP to Ford maverick, Volkswagen Tiguan, Jeep guide, Toyota RAV4 four City SUV, the automobile comprehensive performance evaluation index system was established with the analytic hierarchy process, and the various indicators to analyze the importance ranking, the indicators of automobile comprehensive performance comparis on.

\section{Analytic hierarchy process}

AHP is a complex process of qualitative quantify, put a huge, factors of no order group is subdivided into an orderly hierarchical structure, and compared according to the method of 1-9 index. In order to establish two two comparison judgment matrix; determine the various elements of each layer in the weights using the method of mathematical calculation, and a one-time inspection, to meet the test of consistency conditions, weight synthesis, determine the weight calculation of the target layer and the total sequencing; comprehensive evaluation finally through practical investigation or expert score and weight of all the elements, finally obtains the evaluation results.

\section{SUV automotive performance model based on Analytic Hierarchy Process}

\section{Establish the hierarchical structure model.}

The first layer:The target layer

Second layer: the criterion layer

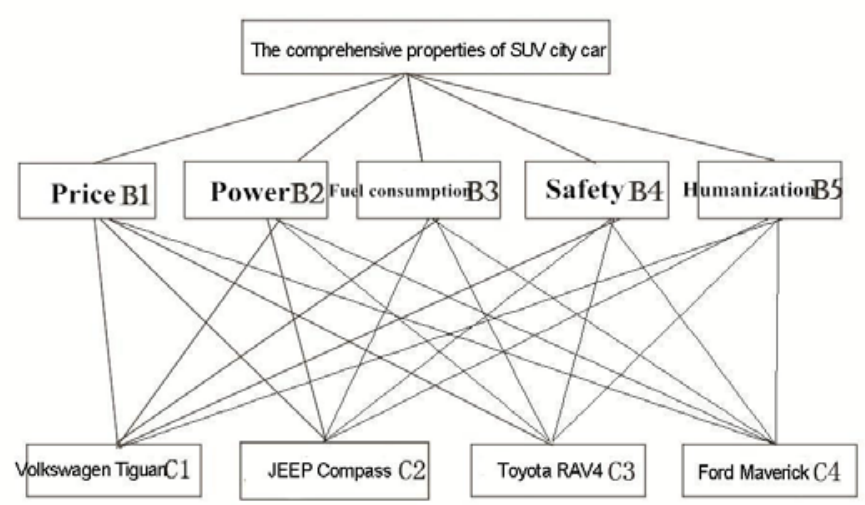

Third layer: plan layer

Fig. 1 The hierarchical structure model 
Establish judgment matrix, determining the weight and the consistency check.Structural criteria layer comparison matrix, the 5 factors of rule layer relative to the target layer two two comparison, to obtain a comparison result.

Table 1 Criteria layer comparison matrix

\begin{tabular}{c|lllll}
\hline & $B_{1}$ & $B_{2}$ & $B_{3}$ & $B_{4}$ & $B_{5}$ \\
\hline$B_{1}$ & 1 & 3 & 1 & $1 / 3$ & 1 \\
$B_{2}$ & $1 / 3$ & 1 & 1 & $1 / 5$ & $1 / 3$ \\
$B_{3}$ & 1 & 1 & 1 & $1 / 3$ & 3 \\
$B_{4}$ & 3 & 5 & 3 & 1 & 1 \\
$B_{5}$ & 3 & 3 & $1 / 3$ & 1 & 1 \\
\hline
\end{tabular}

The determination of weight and the consistency check.Judgment matrix is given and the relative weight between the various interrelated index. Need the validity of judgment matrix consistency tests by mathematical methods, to ensure that the relative importance of each index of judgment matrix can evaluate scientifically. In order to ensure the consistency of the evaluation thinking judgment process, namely to ensure compatibility matrix judgment; judgment matrix consistency index and ratio of CI random CR, must meet the following conditions.

By calculating the maximum characteristic value of $\mathrm{A}=5.132$ judgment matrix.A judgment matrix (AW) I as the vector AW the first I component; RI can determine the random consistency index table look-up table that found by matrix: RI 1.12. The consistency test can be tested by CR value.

Table 2 The average random consistency index table

\begin{tabular}{|c|c|c|c|c|c|c|c|c|c|c|c|c|}
\hline $\begin{array}{c}\text { The order } \\
\text { of matrix }\end{array}$ & 1 & 2 & 3 & 4 & 5 & 6 & 7 & 8 & 9 & 10 & 11 & 12 \\
\hline RI & 0 & 0 & 0.52 & 0.89 & 1.12 & 1.26 & 1.36 & 1.41 & 1.46 & 1.49 & 1.52 & 1.54 \\
\hline
\end{tabular}

$$
\begin{gathered}
C R=\frac{C I}{R I} \approx 0.03<0.1 \\
C I=\frac{\lambda \max -n}{n-1}=0.033
\end{gathered}
$$

This shows that the consistency of the judgment matrix is acceptable.

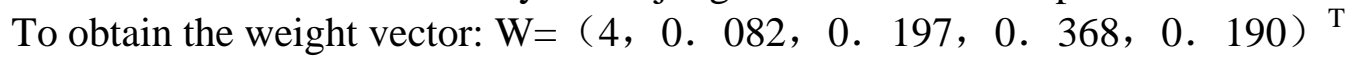

Structure scheme layer of all elements of the criteria layer comparison matrix.

Table 3 According to the comparison result of the price of B1

\begin{tabular}{c|cccc}
\hline & $C_{1}$ & $C_{2}$ & $C_{3}$ & $C_{4}$ \\
\hline$C_{1}$ & 1 & 1 & 2 & $1 / 2$ \\
$C_{2}$ & 1 & 1 & 2 & $1 / 2$ \\
$C_{3}$ & $1 / 2$ & $1 / 2$ & 1 & $1 / 3$ \\
$C_{4}$ & 2 & 2 & 3 & 1 \\
& & & & \\
\hline
\end{tabular}

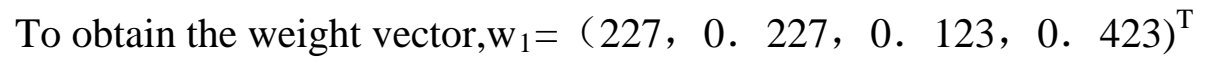


Table 4 According to the comparison result of power B2

\begin{tabular}{c|llll}
\hline & $C_{1}$ & $C_{2}$ & $C_{3}$ & $C_{4}$ \\
\hline$C_{1}$ & 1 & 2 & 1 & $1 / 3$ \\
$C_{2}$ & $1 / 2$ & 1 & $1 / 2$ & $1 / 4$ \\
$C_{3}$ & 1 & 2 & 1 & $1 / 3$ \\
$C_{4}$ & 3 & 4 & 3 & 1 \\
\hline
\end{tabular}

To obtain the weight vector, $\mathrm{w}_{2}=\left(\begin{array}{llll}90 & 0.106,0.190,0.514\end{array}\right)^{\mathrm{T}}$

Table 5 According to the comparison result of fuel consumption B3

\begin{tabular}{c|cccc}
\hline & $C_{1}$ & $C_{2}$ & $C_{3}$ & $C_{4}$ \\
\hline$C_{1}$ & 1 & 3 & 4 & 2 \\
$C_{2}$ & $1 / 3$ & 1 & 2 & $1 / 2$ \\
$C_{3}$ & $1 / 4$ & $1 / 2$ & 1 & $1 / 3$ \\
$C_{4}$ & $1 / 2$ & 2 & 3 & 1 \\
\hline
\end{tabular}

To obtain the weight vector, $\mathrm{w}_{3}=\left(\begin{array}{lllll}466,0.161, & 0.096,0.277\end{array}\right)^{\mathrm{T}}$

Table 6 According to the comparison result of safety B4

\begin{tabular}{c|cccc}
\hline & $C_{1}$ & $C_{2}$ & $C_{3}$ & $C_{4}$ \\
\hline$C_{1}$ & 1 & 3 & 4 & 2 \\
$C_{2}$ & $1 / 3$ & 1 & 2 & $1 / 2$ \\
$C_{3}$ & $1 / 4$ & $1 / 2$ & 1 & $1 / 3$ \\
$C_{4}$ & $1 / 2$ & 2 & 3 & 1 \\
\hline
\end{tabular}

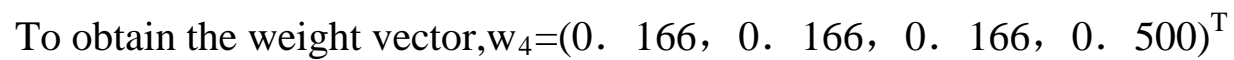

Table 7 According to the comparison result of the humanized configuration B5

\begin{tabular}{c|cccc}
\hline & $C_{1}$ & $C_{2}$ & $C_{3}$ & $C_{4}$ \\
\hline$C_{1}$ & 1 & 3 & 1 & $1 / 2$ \\
$C_{2}$ & $1 / 3$ & 1 & $1 / 3$ & $1 / 4$ \\
$C_{3}$ & 1 & 3 & 1 & $1 / 2$ \\
$C_{4}$ & 2 & 4 & 2 & 1 \\
& & & & \\
\hline
\end{tabular}

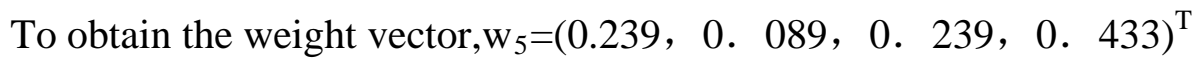

In summary, using ( $\mathrm{C} 1, \mathrm{C} 2, \mathrm{C} 3, \mathrm{C} 4) \mathrm{T}$ said 4 alternative schemes in which occupies in the proportion of target layer, can get the AHP model of several city car based on SUV:

$$
\left(C_{1}, C_{2}, C_{3}, C_{4}\right)^{T}=\left(W_{1}, W_{2}, W_{3}, W_{4}, W_{5}\right)_{4 \times 5} \times W
$$


The data with equation (3):

$$
\begin{aligned}
& =\left[\begin{array}{lllll}
0.227 & 0.190 & 0.466 & 0.166 & 0.239 \\
0.227 & 0.106 & 0.161 & 0.166 & 0.089 \\
0.123 & 0.190 & 0.096 & 0.166 & 0.239 \\
0.423 & 0.514 & 0.277 & 0.500 & 0.433
\end{array}\right] \bullet\left[\begin{array}{l}
0.164 \\
0.082 \\
0.197 \\
0.368 \\
0.190
\end{array}\right] \\
& =\left[\begin{array}{l}
0.251 \\
0.156 \\
0.161 \\
0.432
\end{array}\right]
\end{aligned}
$$

Table 8 The weights

\begin{tabular}{|l|cccc|}
\hline Target weight & 0.432 & 0.251 & 0.161 & 0.156 \\
\hline Sorting & $\mathrm{C}_{4}$ & $\mathrm{C}_{1}$ & $\mathrm{C}_{3}$ & $\mathrm{C}_{2}$ \\
\hline
\end{tabular}

\section{Summary}

This paper discusses the method of comprehensive evaluation method of performance of several city SUV car with hierarchy analysis, the method of establishing the system of automobile comprehensive performance evaluation index with AHP, and the various indicators to analyze sort, the method is simple and convenient. The calculation process from the analysis, can be summarized as follows: 1 . By the total ordering can be seen, in several SUV car performance evaluation of moderate price, considering the Ford maverick in the automobile power, price, fuel consumption, safety and humanization design under the more superior. The comprehensive properties of SUV in the field of automobile design play a role. The application of analytic hierarchy process to evaluate the comprehensive performance of the automobile, in the operation, the decision maker can easily construct the judgment matrix of good quality, with the main objective judgment, evaluation index, evaluation for comprehensive performance of the automobile field can provide a practical, efficient method.

\section{References}

[1] Shulin Liu. On AH P in the exponential scale method [J]. systems engineering theory \& practice, 1995, (10).

[2] QizongWu , Youwen Li . The AHP judgment matrix consistency EJ3. Journal of Beijing Institute of Technology, 1999, (4)

[3] Qiyuan Jiang, a mathematical model of [M]. Beijing: Higher Education Press, 1993 